\title{
COMMENTARY
}

\section{CERTIFIED FIT TO DIVE}

\author{
JEFF WILKS \\ Griffith University Logan Campus, University Drive, Meadowbrook, QLD
}

Scuba diving is one of the world's most popular adventure activities, with the largest training organization PADI issuing an average of 900,000 diving certificates each year (Professional Association of Diving Instructors [PADI], 2016a). Estimates suggest that there are up to 6 million active divers globally (Diving Equipment and Marketing Association [DEMA], 2017). Participants range from age 12 upwards, with the highest proportion of active divers in the 38-53 years age range. Although there are different views about how many dives per year it takes to be "active," it is clear that many people only dive on their vacations (Coghlan \& Prideaux, 2008; Wilks \& Atherton, 1994). In tourist destinations like Queensland, especially on the Great Barrier Reef, up to half of the approximately 1.2 million diving trips and 2.3 million snorkeling trips each year are undertaken by overseas visitors (Ministerial Reference Group, 2011).

Client safety has always been a concern for the dive industry, recognizing that many dive customers may have preexisting health conditions that need to be assessed before they go underwater. For first time divers, those taking an "introductory" or resort scuba experience, there is a standard requirement to complete a medical screening questionnaire that asks candidates "Have you suffered from, or do you now suffer from, any of the following" and a list that includes: asthma or wheezing; fainting, seizures or blackouts; chronic sinus conditions; chest surgery; epilepsy; diabetes mellitus (sugar diabetes); heart disease of any kind; collapsed lung (pneumothorax); and ear surgery (PADI, 2010). High blood pressure, alcohol use in the previous 8 hours, and pregnancy are also on the list. If the answer is "yes" to any of the conditions then the instructor seeks medical advice and the candidate is usually referred to a doctor for a dive medical examination to assess their fitness or suitability for diving.

For those divers who already have their open water certification (called a "C" card), if they have not dived in the previous 12 months the instructor will usually ask that they undertake a pool skills assessment. For those who have not dived for 2 years or more a full scuba review program is often required (PADI, 2016b). In both cases a medical screening questionnaire is used to identify any changes in health status and the need to see a doctor for a diving medical examination.

In most countries there is no requirement to see a doctor before undertaking training for an open water certification. However, in Queensland the Safety in Recreational Water Activities (SRWA) Regulation

Address correspondence to Jeff Wilks, Griffith University Logan Campus, University Drive, Meadowbrook, QLD 4131.

E-mail: j.wilks@griffith.edu.au 
2011 and the Recreational Diving, Recreational Technical Diving and Snorkelling Code of Practice 2011, as amended, require dive medicals from entry-level dive candidates who:

(a) have or have had any of the medical conditions mentioned in the medical declaration; or

(b) are over 45 years old; or

(c) have a body mass index over 30 and a waist circumference greater than $102 \mathrm{~cm}$ for males and $88 \mathrm{~cm}$ for females.

Anyone in these categories will not be allowed to commence training unless they can provide a dive medical certificate from a doctor confirming that they are medically fit to dive.

The recommendations for the above criteria came from the Ministerial Reference Group (2011), which noted that cardiac and underlying coronary conditions are the most significant health issues for persons undertaking diving, with people over the age of 45 at increased risk. The Reference Group adopted two measures to help determine if a person is at increased risk of developing a chronic disease, including cardiac and underlying coronary conditions. The two measures are a body mass index (BMI) and a waist circumference measurement. A person with a BMI over 30 is considered to be obese. A waistline of greater than $102 \mathrm{~cm}$ for most men or $88 \mathrm{~cm}$ for most women is an indicator of internal fat deposits, which can surround the heart, kidneys, liver, and pancreas, and greatly increases the risk of chronic disease (Ministerial Reference Group, 2011, p. 35).

The Reference Group suggested that these measurements are easy to conduct with limited subjectivity, so for candidates presenting with measurements equal or greater to the thresholds it is reasonable for the instructor to conclude an increased risk and require a medical certificate.

Overall, a dive medical is a very valuable way of ensuring that all divers are safe underwater, recognizing that certain medical conditions develop with age and the medications taken for these conditions may be contraindicated for diving. Regular dive medical examinations are recommended every 5 years for those under 30 years of age, every 3 years for those 30-50 years of age, and every year for divers over 50 years of age (Dive Medicals Online, n.d.).

Dive tourism is a multimillion dollar industry that provides excitement and enjoyment for many people. At the same time, the marine environment can be unforgiving if divers have health issues that are not addressed. Industry screening measures and the requirement that anyone who may be at risk consult a doctor are important measures to ensure people are fit to dive.

\section{References}

Coghlan, A., \& Prideaux, B. (2008). Reef tourism first yearly report. Quarterly patterns of reef tourism on the Great Barrier Reef-Northern, Central and Whitsunday areas. Report to the Marine and Tropical Sciences Research Facility, Cairns; Reef and Rainforest Research Centre, James Cook University, Townsville, QLD.

Diving Equipment and Marketing Association. (2017). Fast facts: Recreational scuba diving and snorkeling. Retrieved from http://www.dema.org/store/download.asp? $\mathrm{id}=7811 \mathrm{~B} 097-8882-4707-A 160-\mathrm{F} 999 \mathrm{~B} 49614 \mathrm{~B} 6$

Dive Medicals Online. (n.d.). The dive medical examination. Retrieved from http://www.divemedicals.com.au/ medical.html

Ministerial Reference Group. (2011). Recreational dive and snorkelling industry reference group report to the Minister for Education and Industrial Relations. Brisbane, Australia: Workplace Health and Safety Queensland, Department of Justice and Attorney General.

Professional Association of Diving Instructors. (2010). Discover scuba diving. Retrieved from http://www.dive medicals.com.au/introdive.pdf

Professional Association of Diving Instructors. (2016a). Worldwide corporate statistics 2016: Data for 2010 2015, updated February 2016. Retrieved from https:// www.padi.com/sites/default/files/documents/aboutpadi/statistics/PADI_2016_WW_Statistics.pdf

Professional Association of Diving Instructors. (2016b). Scuba review program. Retrieved from https://www. padi.com/padi-courses/scuba-review-program

Wilks, J., \& Atherton, T. (1994). Fitness to participate in adventure activities: Medical and legal considerations arising from recreational scuba diving. South Pacific Underwater Medicine Society Journal, 24, 137-140. 